\title{
Benzilaminopurina (BAP) e thidiazuron (TDZ) na propagação in vitro de Pfaffia glomerata (Spreng.) Pedersen
}

\author{
FLORES, R. ; NICOLOSO, F.T. ; MALDANER, J. ${ }^{1}$; GARLET, T.M.B. ${ }^{2}$ \\ ${ }^{1}$ Laboratório de Biotecnologia Vegetal, Centro de Ciências Naturais e Exatas (CCNE), Universidade Federal de \\ Santa Maria (UFSM), Avenida Roraima, 1000, Cidade Universitária, Bairro Camobi, Santa Maria, RS, 97105-900. \\ *rejane.flores@terra.com.br, ftnicoloso@yahoo.com, jo_maldaner@yahoo.com.br ${ }^{2}$ Laboratório de Cultura de Tecidos, \\ Universidade de CruzAlta (UNICRUZ), Rua Andrade Neves, 308, Cruz Alta, RS, 98025-810. taneagarlet@hotmail.com
}

\begin{abstract}
RESUMO: Pfaffia glomerata (Spreng.) Pedersen, conhecida como ginseng brasileiro, é muito utilizada pela medicina popular devido suas propriedades fitoterápicas. Este trabalho teve como objetivo avaliar o efeito de concentrações de BAP e de TDZ na propagação in vitro de dois acessos (BRA e JB-UFSM) desta espécie. Segmentos nodais, provenientes de plantas assépticas, foram cultivados em meio Murashige e Skoog (MS) suplementado com 0, 1 e $5 \mu \mathrm{M}$ de BAP ou TDZ. Após 30 dias, as plantas foram transferidas para meio MS não suplementado com citocinina. Observou-se que a organogênese in vitro de P. glomerataé genótipo-dependente. O acesso BRA mostrou um maior potencial para a propagação in vitro em relação ao JB-UFSM. O cultivo dos segmentos nodais do acesso BRA em meio com $1 \mu \mathrm{M}$ de TDZ, seguido pelo subcultivo dos brotos para meio isento de citocininas mostrou ser um método viável para a propagação in vitro devido à alta taxa de multiplicação e o bom desenvolvimento das plantas. No acesso JB-UFSM, o cultivo dos segmentos nodais em meio não acrescido de citocinina mostrou ser o método mais adequado para a produção de um grande número de plantas com alta qualidade.
\end{abstract}

Palavras chave: Amaranthaceae, ginseng brasileiro, cultivo in vitro, citocininas

\begin{abstract}
Benzylaminopurine (BAP) and thidiazuron (TDZ) on in vitro propagation of Pfaffia glomerata (Spreng.) Pedersen. The plant Pfaffia glomerata (Spreng.) Pedersen, known as Brazilian ginseng, is extensively used in folk medicine due to its phytotherapic characteristics. This work aimed to evaluate the effect of BAP and TDZ concentrations on the in vitro propagation of two sources (BRA and JB-UFSM) of this species. Nodal segments originated from aseptically grown plants were cultured on Murashige and Skoog (MS) medium supplemented with 0, 1 and 5 $\mu \mathrm{M} B A P$ or TDZ. After 30 days, the plants were transferred to MS medium without cytokinin. The in vitro organogenesis of $P$. glomerata is genotype-dependent. The source BRA had greater potential for in vitro propagation than JB-UFSM. The culture of BRA nodal segments on medium with $1 \mu \mathrm{M}$ TDZ, followed by subcultivation of sprouts on cytokinin-free medium, showed to be a viable method for in vitro propagation due to high multiplication rate and good plant development. In the source JB-UFSM, the culture of nodal segments on medium without cytokinin was the best method to obtain a large number of high-quality plants.
\end{abstract}

Key words: Amaranthaceae, Brazilian ginseng, in vitro culture, cytokinins

\section{INTRODUÇÃO}

O gênero Pfaffia (Amaranthaceae) engloba cerca de 90 espécies naturais da América Central e América do Sul, incluindo vários Estados do Brasil. Várias espécies desse gênero são conhecidas como ginseng brasileiro, pois as raízes têm sido utilizadas como adaptógenas e afrodisíacas, bem como para o tratamento de diabetes, reumatismo, esgotamento físico e mental, falta de memória e estresse (Rates \& Gosmann, 2002).

P. glomerataé a espécie de maior importância medicinal e comercial, cujas raízes são utilizadas como matéria prima para a produção de fitoterápicos e suplementos alimentares (Figueiredo et al., 2004; Zimmer et al., 2006). Estudos farmacológicos

Recebido para publicação em 23/06/2008

Aceito para publicação em 15/11/2008

Rev. Bras. PI. Med., Botucatu, v.11, n.3, p.292-299, 2009. 
demonstraram que extratos de raízes de $P$. glomerata favoreceram a aprendizagem e a memória (Marques et al., 2004), apresentaram efeitos antiinflamatórios, analgésicos (Neto et al., 2005) e antioxidantes (Daniel et al., 2005). Freitas et al. (2003) constataram que extratos das raízes de $P$. glomerata protegeram a mucosa gástrica, confirmando o uso popular da planta no tratamento de distúrbios gástricos. Além disso, pesquisas conduzidas com extratos fracionados de raízes de $P$. glomerata demonstraram a atividade antihiperglicemiante da planta (Sanches et al., 2001). Estes efeitos farmacológicos de $P$. glomerata são atribuídos à presença de vários compostos químicos isolados a partir das raízes das plantas, destacandose as saponinas triterpênicas e os fitoecdisteróides (Shiobara et al., 1993).

Em virtude das propriedades medicinais, tem havido intensa exploração das reservas naturais de $P$. glomerata, pondo em risco a variabilidade genética das populações naturais, uma vez que existem poucas áreas de cultivo comercial. Conforme Figueiredo et al. (2004), as ameaças às populações de P. glomerata são decorrentes, principalmente, do uso das raízes da planta e do extrativismo, sendo necessários estudos urgentes visando o cultivo comercial da espécie. Neste sentido, várias pesquisas vêm sendo realizadas no intuito de desenvolver planos de manejo e estratégias de cultivo para essa espécie. A propagação de plantas homogêneas de $P$. glomerata via estaquia, em condições de viveiro e hidroponia, embora sendo viável, produz um número de mudas pouco expressivo (Nicoloso et al., 1999).

Em plantas medicinais, a cultura de tecidos tem auxiliado na produção comercial de mudas homogêneas e de qualidade, na conservação do germoplasma, além de auxiliar na seleção e melhoramento de genótipos com potencial para ser utilizados pela indústria farmacêutica (Rao \& Ravishankar, 2002). Um eficiente protocolo de micropropagação de P. glomerata foi desenvolvido por Nicoloso et al. (2001), cultivando-se segmentos nodais em meio MS não suplementado com fitoreguladores. Porém, em muitas culturas, o crescimento e a proliferação de brotos in vitro a partir de gemas axilares é maximizado pela incorporação de citocininas ao meio nutritivo (George, 1996). As citocininas são muito importantes na regulação do crescimento e da morfogênese, pois estimulam a divisão das células, a indução e a proliferação de brotações (Howell et al., 2003). Segundo Mok et al. (1987), de acordo com a estrutura química, as citocininas são classificadas em dois grupos: as derivadas da adenina (como a 6-benzilaminopurinaBAP) e as derivadas das feniluréias (como o N-phenylN'-1,2,3-thidiazol-5-ylurea - Thidiazuron, TDZ). Em geral, meios acrescidos com BAP têm sido utilizados no cultivo in vitro de espécies de amarantáceas
(Bennici et al., 1997). O TDZ apresenta propriedades biológicas similares àquelas das citocininas (Mok et al., 1987) quando adicionado ao meio nutritivo, sendo muito utilizado na propagação clonal de plantas medicinais (Arikat et al., 2004), inclusive de Pfaffia tuberosa (Spreng.) Hicken (Flores et al., 2007). Considerando que estudos sobre os efeitos morfogênicos das citocininas são incipientes no gênero, este trabalho teve como propósito estudar o efeito da BAP e do TDZ na propagação in vitro de dois acessos de Pfaffia glomerata.

\section{MATERIAL E MÉTODO}

O ensaio foi conduzido no Laboratório de Biotecnologia Vegetal, pertencente ao Departamento de Biologia da Universidade Federal de Santa Maria (UFSM), Santa Maria, RS.

\section{Material vegetal e condições de cultivo}

Utilizaram-se plantas dos acessos BRA e JB-UFSM de $P$. glomerata (Spreng.) Pedersen (Amaranthaceae). O acesso BRA foi coletado no município de Querência do Norte, PR e o acesso JBUFSM faz parte do acervo do Jardim Botânico da UFSM (Santa Maria, RS). Exsicatas encontram-se depositadas no Herbário do Departamento de Biologia sob o número de SMDB 7606.

O material vegetal utilizado no ensaio consistiu de plantas estabelecidas in vitro, com 30 dias de idade, as quais foram multiplicadas, a partir de segmentos caulinares, em meio MS (Murashige \& Skoog, 1962) suplementado com sacarose (30 g $\left.\mathrm{L}^{-1}\right)$, mio-inositol (100 mg L-1) e ágar $\left(6 \mathrm{~g} \mathrm{~L}^{-1}\right)$, segundo metodologia descrita Nicoloso et al. (2001). O pH foi ajustado para 5,9 e o meio foi autoclavado (1atm, $\left.120^{\circ} \mathrm{C}\right)$ durante 20 minutos. A inoculação e a repicagem das culturas foram realizadas em câmara de fluxo laminar, em condições assépticas, colocando-se um explante por tubo de ensaio $(25 \mathrm{~mm}$ de diâmetro, $150 \mathrm{~mm}$ de altura e $147,26 \mathrm{~cm}^{3}$ de volume interno). As plantas foram cultivadas em sala de crescimento com temperatura de $25 \pm 2^{\circ} \mathrm{C}$, 16 horas de fotoperíodo e $35 \mu \mathrm{M} \mathrm{m}^{-2} \mathrm{~s}^{-1}$ de luminosidade.

\section{Efeito das citocininas BAP e TDZ na propagação in vitro}

Segmentos nodais $(1 \mathrm{~cm}$ e com duas gemas axilares) de plantas homogêneas de ambos os acessos (BRA e JB-UFSM) de P. glomerata foram cultivados em meio MS suplementado com três concentrações $(0,1$ e $5 \mu \mathrm{M})$ de BAP ou TDZ. Os explantes foram inoculados verticalmente em tubos de ensaio, contendo $10 \mathrm{~mL}$ de meio nutritivo.

Visando favorecer o alongamento e o enraizamento, após trinta dias de cultivo nas diferentes concentrações de BAP ou TDZ, os segmentos nodais dos brotos regenerados foram seccionados e 
transferidos para tubos de ensaio contendo 10 $\mathrm{mL}$ de meio $M S$ não suplementado com citocinina.

O material foi avaliado aos 30 dias após cada inoculação através do número médio de brotações, número médio de segmentos nodais, comprimento dos brotos $(\mathrm{cm})$, coloração das brotações e percentagem de enraizamento. Para a avaliação da variável coloração da parte aérea, aplicaram-se os valores 1,3 e 5 correspondentes a brotos com coloração vermelho-violácea, brotos como coloração verde e vermelho-violácea pouco intensa e brotos verdes, respectivamente, conforme metodologia adaptada de Flores et al. (1999).

Utilizaram-se cinco repetições, sendo cada repetição formada por dez explantes. $O$ delineamento experimental utilizado foi o inteiramente ao acaso. Os dados foram submetidos à análise de variância e analisados pelo teste de Tukey, ao nível de $1 \%$ de probabilidade pelo teste $F$. Os dados expressos em percentagem foram transformados segundo arco seno raiz quadrada de (X/100), onde X significa o valor percentual obtido. Para as variáveis, número de brotações e segmentos nodais, os dados foram transformados segundo a raiz quadrada de $(X+1)$, onde $X$ é $o$ valor obtido por contagem.

\section{RESULTADOE DISCUSSÃO}

Observou-se o desenvolvimento de brotações axilares em todos os tratamentos testados. Após 30 dias de cultivo in vitro, verificou-se um acréscimo significativo no número médio de brotações no material cultivado em meio contendo BAP ou TDZ (Tabela 1). O melhor resultado foi observado no acesso BRA na presença de $1 \mu \mathrm{M}$ de TDZ, com média de 3,3 brotações por explante, enquanto que no acesso JB-UFSM, o maior número médio de brotos foi registrado em meio acrescido de 1 ou $5 \mu \mathrm{M}$ de TDZ, cujo valor foi inferior ao observado no acesso BRA (Tabela 1). O efeito do TDZ na proliferação de brotos de $P$. glomerata está de acordo com os resultados descritos por Flores et al. (2007) em Pfaffia tuberosa (Spreng.) Hicken.

Por outro lado, maior número médio de segmentos nodais foi observado no acesso BRA quando cultivado em meio suplementado com $1 \mu \mathrm{M}$ BAP $(6,4$ segmentos nodais por planta) ou isento de citocinina ( 6,3 segmentos nodais por planta). Os explantes provenientes do acesso JB-UFSM apresentaram um maior número de segmentos nodais em meio acrescido de $1 \mu \mathrm{M}$ BAP $(6,2$ segmentos nodais por planta) (Tabela 1). Desta forma, a BAP mostrou-se mais eficaz que o TDZ na formação de segmentos nodais, especialmente no acesso JB-UFSM. Segundo Mantell et al. (1994), as taxas de multiplicação, em geral, de 5-10x, variam de acordo com o genótipo e composição do meio de cultura. A produção de segmentos nodais é um parâmetro importante na propagação in vitro de $P$. glomerata, pois reflete a produção de novas plantas a cada subcultivo e, de acordo com Zaerr \& Mapes (1985), BAP é a citocinina mais eficaz para a multiplicação de partes aéreas da maioria das espécies.

De modo geral, a adição de citocinina ao meio nutritivo reduziu o crescimento das brotações. Em ambos os acessos, a redução no comprimento dos brotos foi maior em meio com TDZ quando comparado a BAP (Tabela 1). Em geral, o efeito negativo do TDZ no crescimento das brotações in vitroé maior quando comparado às citocininas derivadas da adenina (Mok et al., 1987). O TDZ também induziu brotos pouco alongados em Cajanus cajan L. (Eapen et al., 2004), Lens culinaris Medik (Khawar et al., 2004) e Pfaffia tuberosa (Spreng.) Hicken (Flores et al., 2007). Segundo Huetteman \& Preece (1993), o efeito do TDZ no alongamento dos brotos está relacionado com sua alta atividade e estabilidade nos tecidos.

De forma semelhante ao observado por Nicoloso et al. (2001), verificou-se que as plantas cultivadas em meio MS não suplementado com reguladores de crescimento apresentaram morfologia similar às plantas matrizes, com a coloração verde predominando na superfície adaxial das folhas (Figura 1).

No entanto, a adição de citocinina ao meio de cultura modificou a coloração das brotações regeneradas em ambos os acessos de P. glomerata (Tabela 1 e Figura 2). A presença da BAP ou do TDZ promoveu um incremento na coloração vermelho-violácea nos brotos em detrimento do verde. Observou-se um aumento significativo na intensidade da coloração vermelho-violácea à medida que $\mathrm{a}$ concentração do BAP aumentou no meio de cultura (Tabela 1 e Figuras 2A, 2B, 2C, 2D), sendo os brotos com maiores alterações na coloração registrados no acesso BRA em meio acrescido de $5 \mu \mathrm{M}$ de BAP (Tabela 1 e Figura $2 \mathrm{C}$ ). No acesso JB-UFSM, este tratamento também alterou significativamente a coloração das brotações, porém a coloração vermelhoviolácea não foi tão intensa quanto à observada no acesso BRA (Tabela 1 e Figuras 2D). Ao contrário da BAP, o TDZ afetou de forma menos intensa a coloração das brotações, diferindo significativamente do BAP nas concentrações $1 \mathrm{e}$ $5 \mu \mathrm{M}$ (Tabela 1 e Figuras 2C, 2G). A maioria dos brotos do genótipo BRA cultivados na presença de TDZ apresentaram folhas verdes com pecíolos e talos pigmentados de vermelho (Figuras 2E, 2G), enquanto que no JB-UFSM, as plantas apresentaram coloração verde (Figura $2 F$ ), exceto na concentração $5 \mu \mathrm{M}$ de TDZ (Figura 2H). A coloração vermelho-violácea presente em P. glomerata e em outras 


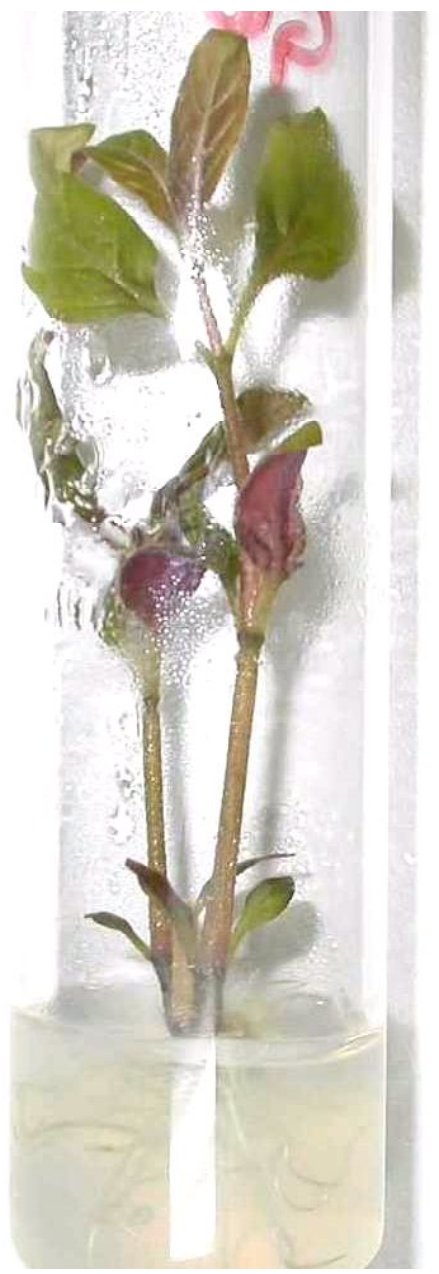

FIGURA 1. Aspecto geral de planta de Pfaffia glomerata (acesso BRA) cultivada in vitro, em meio MS, durante 30 dias.

espécies pertencentes à família Amaranthaceae, é decorrente do pigmento betalaína (Cronquist, 1981). Recentemente, espécies pertencentes aos gêneros Amaranthus, Gomphrena e Celosia vêm sendo exploradas como fonte de betalaína, o qual é utilizado como corante e antioxidante pela indústria alimentícia (Cai et al., 2005). Nos dias atuais, o potencial de $P$. glomerata como fonte de betalaína é pouco estudado. Contudo, os resultados obtidos no presente estudo mostraram que a presença de citocininas exógenas pode interferir no metabolismo dos pigmentos de Pfaffia glomerata, o que mostrou ser dependente do acesso, do tipo e da concentração da citocinina utilizada no meio nutritivo. Estas informações poderão fornecer subsídios para futuras pesquisas tendo em vista a exploração dessa espécie como fonte de betalaína.

Uma alta percentagem de enraizamento foi observada nos brotos cultivados em meio MS não acrescido de citocinina, enquanto que na presença da BAP ou do TDZ houve uma redução significativa no enraizamento dos brotos (Tabela 1 ). A concentração de $1 \mu \mathrm{M}$ de BAP proporcionou um maior enraizamento quando comparada a mesma concentração de TDZ, demonstrando que, em concentrações reduzidas, esta citocinina pode prejudicar a formação de raízes (Tabela 1 ). O efeito inibitório das citocininas e, em especial, do TDZ na regeneração de raízes e no alongamento de brotosé relatado em várias espécies (Huetteman \& Preece, 1993; Khawar et al., 2004; Eapen et al., 2004; Flores et al., 2007). Esses efeitos podem ser explicados pelo fato do TDZ alterar o metabolismo de citocininas naturais, culminado no aumento do teor endógeno de citocinina (Mok et al., 1987).

O presente estudo mostrou que as concentrações de BAP ou TDZ incrementaram a regeneração de brotações, sendo os melhores resultados obtidos com o TDZ e no acesso BRA de P. glomerata. Apesar de o TDZ ter sido superior ao BAP na proliferação de brotos, esta citocinina mostrou-se mais eficaz que o TDZ na formação de segmentos nodais, especialmente no acesso JBUFSM. Em ambos os acessos, a adição de citocinina reduziu o comprimento, alterou a pigmentação dos brotos e reduziu o enraizamento. Além disso, observou-se uma redução no tamanho das folhas do acesso BRA, quando cultivado em meio contendo 5 $\mu \mathrm{M}$ de BAP (Figura $2 \mathrm{C}$ ) ou $5 \mu \mathrm{M}$ de TDZ (Figura $2 \mathrm{G}$ ), o que demonstra que concentrações superiores a esta podem causar toxidez aos explantes.

As citocininas são muito utilizadas durante a fase de multiplicação in vitro, pois promovem a quebra da dominância apical, maximizam o número de brotos regenerados, favorecendo a propagação in vitro; no entanto, em concentrações não adequadas, podem causar distúrbios fisiológicos característicos nas plantas, como redução no alongamento, encurtamento dos entrenós, vitrificação, inibição do enraizamento, entufamento e outros (George, 1996). Segundo Pattnaik et al. (1996) e Huetteman \& Preece (1993), concentrações inferiores a $5 \mu \mathrm{M}$ de BAP e 1 $\mu M$ de TDZ são eficientes para a proliferação e crescimento de brotos in vitro, no entanto teores mais elevados reduzem o comprimento dos brotos, o tamanho das folhas e inibem o enraizamento. De acordo com Flores et al. (2007), uma alternativa para minimizar os efeitos das citocininas no crescimento da parte aérea e no enraizamento de plantas in vitro é a transferência dos brotos para um meio nutritivo isento de regulador de crescimento.

Houve declínio na produção de brotos quando os explantes foram transferidos para meio MS não suplementado com fitoreguladores (Tabelas $1 \mathrm{e} 2$ ), embora os resultados obtidos com o acesso BRA na presença de $1 \mu \mathrm{M}$ de TDZ (média de 2,0 brotações por planta) e com o acesso JB-UFSM com $5 \mu \mathrm{M}$ de 
TABELA 1. Morfogênese em segmentos nodais de dois acessos de Pfaffia glomerata, cultivados em meio MS suplementado com concentrações de BAP ou TDZ, durante 30 dias.

\begin{tabular}{|c|c|c|c|c|c|c|c|}
\hline Acesso & $\begin{array}{l}\text { Citocinina } \\
\qquad(\mu \mathrm{M})\end{array}$ & & $\begin{array}{l}\text { Número de } \\
\text { brotações* }\end{array}$ & $\begin{array}{l}\text { Número de } \\
\text { segmentos } \\
\text { nodais* }\end{array}$ & $\begin{array}{l}\text { Comprimento } \\
\text { dos brotos } \\
(\mathrm{cm})^{*}\end{array}$ & $\begin{array}{l}\text { Coloração das } \\
\text { brotaçōes*,** }\end{array}$ & $\begin{array}{c}\text { Enraizamento } \\
(\%)^{\star}\end{array}$ \\
\hline \multirow{6}{*}{ BRA } & \multirow{3}{*}{ BAP } & 0 & $1,7 d$ & $6,3 a b$ & 6,7 a & $5,0 \mathrm{a}$ & $100 \mathrm{a}$ \\
\hline & & 1 & $2,6 \mathrm{~b}$ & $6,4 \mathrm{a}$ & $2,0 \mathrm{~d}$ & $2,0 \mathrm{f}$ & $70,0 \mathrm{~b}$ \\
\hline & & 5 & $2,6 \mathrm{~b}$ & $6,2 \mathrm{~b}$ & $1,3 e$ & $1,0 \mathrm{~g}$ & $0 \mathrm{~d}$ \\
\hline & \multirow{3}{*}{ TDZ } & 0 & $1,7 d$ & $6,3 a b$ & $6,7 \mathrm{a}$ & $5,0 \mathrm{a}$ & $100 \mathrm{a}$ \\
\hline & & 1 & $3,3 \mathrm{a}$ & $5,2 d$ & $0,6 \mathrm{~h}$ & $4,5 \mathrm{c}$ & $20,0 \mathrm{c}$ \\
\hline & & 5 & $2,7 b$ & $4,5 \mathrm{e}$ & $0,8 \mathrm{~g}$ & $4,5 \mathrm{c}$ & $0 \mathrm{~d}$ \\
\hline \multirow{6}{*}{$\begin{array}{l}\text { JB- } \\
\text { UFSM }\end{array}$} & \multirow{3}{*}{ BAP } & 0 & $1,4 \mathrm{e}$ & $5,0 d$ & $6,2 \mathrm{~b}$ & $5,0 a$ & $100 \mathrm{a}$ \\
\hline & & 1 & $2,3 \mathrm{c}$ & $6,2 \mathrm{~b}$ & $2,0 \mathrm{~d}$ & $4,0 \mathrm{~d}$ & $100 \mathrm{a}$ \\
\hline & & 5 & $2,2 \mathrm{c}$ & $5,6 \mathrm{c}$ & $2,3 c$ & $3,0 \mathrm{e}$ & $0 \mathrm{~d}$ \\
\hline & \multirow{3}{*}{ TDZ } & 0 & $1,4 e$ & $5,0 d$ & $6,2 \mathrm{~b}$ & $5,0 \mathrm{a}$ & $100 a$ \\
\hline & & 1 & $2,6 \mathrm{~b}$ & $2,7 \mathrm{~g}$ & $0,7 \mathrm{gh}$ & $5,0 \mathrm{a}$ & $0 d$ \\
\hline & & 5 & $2,6 b$ & $4,2 f$ & $1,1 \mathrm{f}$ & $4,8 \mathrm{~b}$ & $0 \mathrm{~d}$ \\
\hline
\end{tabular}

* Médias seguidas de mesma letra não diferem entre si, pelo Teste de Tukey, em nível de 1\% de probabilidade de erro. ** Onde: $1=$ brotos com coloração vermelho-violácea; $3=$ brotos com coloração verde e vermelho-violácea pouco intensa e $5=$ brotos com coloração verde.

BAP ou TDZ (média de 1,7 e 1,6 brotações, respectivamente) tenham sido superiores em relação àquele obtido na ausência de citocinina (Tabela 2). Estes tratamentos também favoreceram o número de segmentos nodais regenerados pelas plantas. No acesso BRA, o uso de $1 \mu \mathrm{M}$ de TDZ aumentou significativamente a formação de novos segmentos nodais $(11,8$ segmentos nodais por planta), já a BAP reduziu o número de segmentos nodais após subcultivo para meio isento de citocininas (Tabela 2). No acesso JBUFSM, a concentração de $5 \mathrm{mM}$ de BAP ou de TDZ foi superior às demais concentrações testadas na regeneração de segmentos nodais (Tabela 2).

O subcultivo do material em meio isento de citocininas favoreceu o crescimento das plantas em ambos os acessos (Tabelas 1 e 2), contudo o comprimento da maioria dos brotos foi inferior ao registrado no material cultivado na ausência de citocinina (Tabela 2). Ao contrário, as plantas do acesso BRA, inicialmente regeneradas com $1 \mu \mathrm{M}$ de TDZ, apresentaram maior crescimento (média de $7,6 \mathrm{~cm}$ ) em relação aos demais tratamentos (Tabela 2). Estes resultados são corroborados com os de Mok et al. (1987) e Flores et al. (2007) que sugerem que os efeitos benéficos das citocininas na organogênese persistiram após o subcultivo das plantas.

A transferência das brotações para meio isento de reguladores vegetais também favoreceu a regeneração do sistema radicular e de brotações com coloração verde (Tabela 2). Contudo, as plantas pertencentes ao acesso BRA, regeneradas com 5 $\mu \mathrm{M}$ de BAP ou TDZ, apresentaram folhas com coloração vermelho-violácea pouco intensa (Tabela 2). Independente do tipo de citocinina, a concentração de $5 \mu \mathrm{M}$ também reduziu a percentagem de plantas enraizadas nesse acesso, sendo que os resultados obtidos com o BAP (80\%) foram superiores aos registrados com o TDZ (50\%). No acesso JB-UFSM, todosos brotosformados apresentaram coloração verde e sistema radicular, independente da concentração e tipo de citocinina utilizada anteriormente (Tabela 2).

Os resultados obtidos no presente estudo mostraram que os efeitos negativos das citocininas no crescimento e coloração dos brotos, bem como no desenvolvimento do sistema radicular foram, em geral, sanados após a transferência do material para meio isento de citocinina. Neste caso, a maioria das plantas apresentou brotações vigorosas e raízes bem desenvolvidas, sendo morfologicamente semelhantes às plantas matrizes (Figura 1), o que segundo Huetteman \& Preece (1993), pode ser explicado pela redução dos níveis de citocininas durante o subcultivo. Similarmente, em Pfaffia tuberosa (Spreng.) Hicken, as citocininas têm sido utilizadas apenas na fase de multiplicação, sendo o alongamento e o enraizamento dos brotos conduzidos em meio isento de fitoreguladores (Flores et al., 2007). Entretanto, neste estudo com P. glomerata e, principalmente no acesso BRA, a concentração $5 \mu \mathrm{M}$ mostrou-se excessiva e deve ser evitada durante a propagação in vitro, pois 

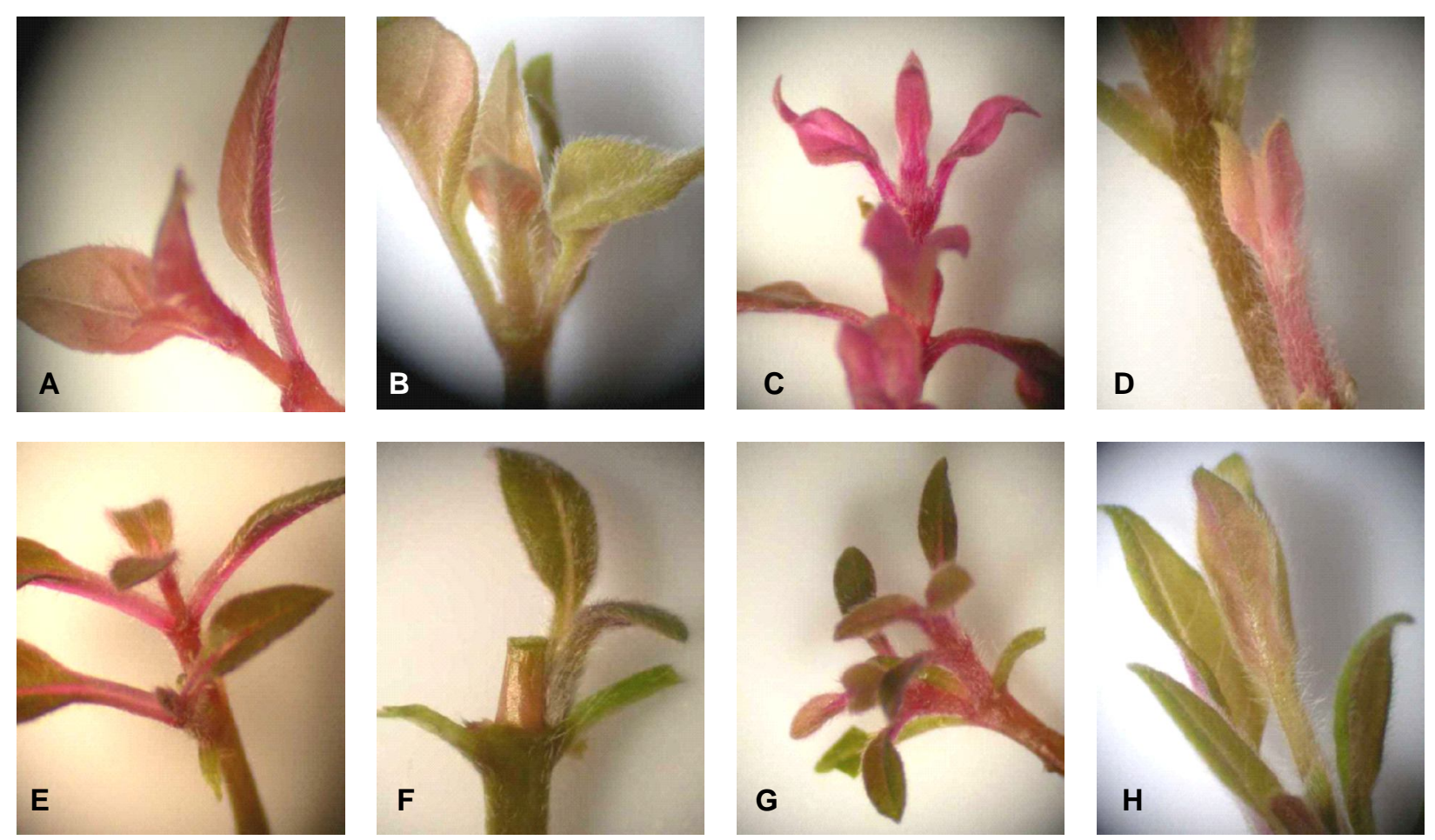

FIGURA2. Aspecto geral de brotações de dois acessos de P. glomerata cultivadas em meio MS suplementado com BAP ou TDZ, durante 30 dias. A) Brotações do acesso BRA, cultivadas em meio MS acrescido de $1 \mu \mathrm{M}$ de BAP (2,5X); B) Brotos do acesso JB-UFSM, cultivados em meio MS suplementado com $1 \mu \mathrm{M}$ de BAP (2,5X); C) Brotações do acesso BRA regeneradas em meio MS com $5 \mu$ M de BAP (2,5X); D) Brotações do acesso JB-UFSM, cultivados em meio MS acrescido de $5 \mu \mathrm{M}$ de BAP (2,5X); E) Brotos do acesso BRA, regenerados em meio MS acrescido de $1 \mu \mathrm{M}$ de TDZ (2,5X); F) Brotações do acesso JB-UFSM, cultivadas em meio MS acrescido de $1 \mu \mathrm{M}$ de TDZ (2,5X); G) Brotações do acesso BRA, cultivadas em meio MS acrescido de $5 \mu \mathrm{M}$ de TDZ (2,5X); H) Brotações de $P$. glomerata, acesso JB-UFSM, cultivadas em meio MS acrescido de $5 \mu \mathrm{M}$ de TDZ (2,5X).

prejudicou desenvolvimento normal das plantas, mesmo após subcultivo para meio isento de citocinina (Tabela 2).

As diferenças morfogênicas entre os acessos BRAe JB-UFSM de P. glomerata mostraramse evidentes em todos os parâmetros estudados (Tabelas 1 e 2). Diferenças morfogênicas entre genótipos são muito freqüentes e já foram observadas em várias espécies propagadas in vitro (Bennici et al., 1997). De acordo com a produção de segmentos nodais, constatou-se que o acesso BRA apresenta um maior potencial para a multiplicação in vitro em relação ao JB-UFSM (Tabelas 1 e 2), podendo ser propagado em meio MS não acrescido de fitoreguladores, cuja produção média é de 6,3 segmentos nodais a cada 30 dias. Adicionalmente, verificou-se que o cultivo do acesso BRA em meio com $1 \mu \mathrm{M}$ de TDZ, seguido pelo subcultivo em meio sem fitoreguladores, aumentou significativamente a produção de segmentos nodais e, consequentemente, a produção de plantas in vitro. Assim, considerandose que são produzidos, em média, 5,2 novos segmentos nodais por planta na fase de multiplicação com $1 \mu \mathrm{M}$ de TDZ e 11,8 segmentos nodais após subcultivo em meio isento de reguladores vegetais, cerca de 60 plantas completas in vitro poderão ser obtidas de um único explante dentro de um período de 2 meses. Desta forma, esta metodologia poderá ser utilizada, alternativamente, para a produção rápida de um grande número de plantas desse acesso de $P$. glomerata. Da mesma forma, em $P$. tuberosa (Spreng.) Hicken, plantas regeneradas com $1 \mu \mathrm{M}$ de TDZ apresentaram alta taxa de multiplicação e bom desenvolvimento das raízes e partes aéreas (Flores et al., 2007).

Por outro lado, os resultados mostraram que maior produção de plantas no acesso JB-UFSM foi obtida na presença de $5 \mu \mathrm{M}$ de BAP, sendo registrado uma média de 5,6 e 5,4 segmentos nodais na fase de multiplicação e após subcultivo em meio isento de citocinina, respectivamente (Tabelas 1 e 2). Contudo, essas plantas apresentaram menor crescimento (média de $3,1 \mathrm{~cm}$ ) quando comparadas às plantas regeneradas na ausência de citocinina 
TABELA2. Morfogênese em segmentos nodais provenientes de plantas de dois acessos de Pfaffia glomerata, inicialmente regeneradas em meio com BAP ou TDZ e após subcultivados, durante 30 dias, em meio MS não suplementado com citocinina.

\begin{tabular}{|c|c|c|c|c|c|c|c|}
\hline Acesso & $\begin{array}{l}\text { Citocinina } \\
\qquad(\mu \mathrm{M})\end{array}$ & & $\begin{array}{l}\text { Número de } \\
\text { brotações* }\end{array}$ & $\begin{array}{l}\text { Número de } \\
\text { segmentos } \\
\text { nodais }^{*}\end{array}$ & $\begin{array}{l}\text { Comprimento } \\
\text { dos brotos } \\
(\mathrm{cm})^{*}\end{array}$ & $\begin{array}{l}\text { Coloração das } \\
\text { brotações }^{*},{ }^{* *}\end{array}$ & $\begin{array}{c}\text { Enraizamento } \\
(\%)^{*}\end{array}$ \\
\hline \multirow{6}{*}{ BRA } & \multirow{3}{*}{ BAP } & 0 & $1,6 \mathrm{~b}$ & $6,0 \mathrm{~b}$ & $6,6 \mathrm{~b}$ & $5,0 a$ & $100 \mathrm{a}$ \\
\hline & & 1 & $1,2 \mathrm{~d}$ & $4,5 \mathrm{~g}$ & $4,1 \mathrm{~d}$ & $5,0 \mathrm{a}$ & $100 \mathrm{a}$ \\
\hline & & 5 & $1,3 \mathrm{~cd}$ & $4,1 \mathrm{~h}$ & $3,7 \mathrm{e}$ & $4,5 b$ & $80,0 \mathrm{~b}$ \\
\hline & \multirow{3}{*}{ TDZ } & 0 & $1,6 \mathrm{~b}$ & $6,0 \mathrm{~b}$ & $6,6 \mathrm{~b}$ & $5,0 \mathrm{a}$ & $100 a$ \\
\hline & & 1 & $2,0 \mathrm{a}$ & $11,8 \mathrm{a}$ & $7,6 \mathrm{a}$ & $5,0 a$ & $100 \mathrm{a}$ \\
\hline & & 5 & $1,2 \mathrm{~d}$ & $5,6 \mathrm{c}$ & $3,7 \mathrm{e}$ & $4,0 \mathrm{c}$ & $50,0 \mathrm{c}$ \\
\hline \multirow{6}{*}{$\begin{array}{l}\text { JB- } \\
\text { UFSM }\end{array}$} & \multirow{3}{*}{ BAP } & 0 & $1,4 \mathrm{c}$ & $5,0 \mathrm{f}$ & $6,0 \mathrm{c}$ & $5,0 \mathrm{a}$ & $100 \mathrm{a}$ \\
\hline & & 1 & $1,2 \mathrm{~d}$ & $3,2 \mathrm{j}$ & $3,1 \mathrm{f}$ & $5,0 \mathrm{a}$ & $100 \mathrm{a}$ \\
\hline & & 5 & $1,7 \mathrm{~b}$ & $5,4 \mathrm{~d}$ & $3,1 \mathrm{f}$ & $5,0 \mathrm{a}$ & $100 \mathrm{a}$ \\
\hline & \multirow{3}{*}{ TDZ } & 0 & $1,4 \mathrm{c}$ & $5,0 \mathrm{f}$ & $6,0 \mathrm{c}$ & $5,0 \mathrm{a}$ & $100 \mathrm{a}$ \\
\hline & & 1 & $1,0 \mathrm{e}$ & $3,4 i$ & $2,4 \mathrm{~g}$ & $5,0 \mathrm{a}$ & $100 \mathrm{a}$ \\
\hline & & 5 & $1,6 \mathrm{~b}$ & $5,2 \mathrm{e}$ & $2,4 \mathrm{~g}$ & $5,0 \mathrm{a}$ & $100 \mathrm{a}$ \\
\hline
\end{tabular}

* Médias seguidas de mesma letra não diferem entre si, pelo Teste de Tukey, em nível de $1 \%$ de probabilidade de erro. ${ }^{* *}$ Onde: $1=$ brotos com coloração vermelho-violácea; $3=$ brotos com coloração verde e vermelho-violácea pouco intensa e $5=$ brotos com coloração verde.

(média de $6 \mathrm{~cm}$ ) (Tabela 2). De fato, várias pesquisas conduzidas com esse acesso de P. glomerata relatam a viabilidade de produzir plantas homogêneas e de qualidade através da micropropagação de segmentos nodais em meio MS (Nicoloso et al., 2001).

Os resultados obtidos no presente estudo permitiram concluir que: a) as respostas in vitro de $P$. glomerata variam de acordo com o acesso; b) o cultivo dos segmentos nodais do acesso BRA, em meio MS suplementado com $1 \mu \mathrm{M}$ de TDZ, seguido do subcultivo dos brotos em meio isento de reguladores vegetais é uma metodologia viável para a produção rápida de um grande número de mudas ec) no acesso JB-UFSM, o cultivo das plantas em meio MS não acrescido de reguladores de crescimento favorece a propagação in vitro.

\section{AGRADECIMENTO}

Os autores agradecem à Coordenação de Aperfeiçoamento de Pessoal de Nível Superior (CAPES) pelo auxílio financeiro e a Embrapa Recursos Genéticos e Biotecnologia pelo fornecimento do acesso BRA de Pfaffia glomerata.

\section{REFERÊNCIA}

ARIKAT, N.A. et al. Micropropagation and accumulation of essencial oils in wild sage (Salvia fruticulosa Mill.). Scientia Horticulturae, v.100, p.193-202, 2004.

BENNICI, A. et al. Studies on callus growth and morphogenesis in several species and lines of Amaranthus. Plant Cell, Tissue and Organ Culture, v.49, p.29-33, 1997.

CAI, Y.; SUN, M.; CORKE, H. Characterization and application of betalain pigments from plants of the Amaranthaceae. Trends in Food Science \& Technology, v.16, p.370-6, 2005.

CRONQUIST, A. An integrated system of classification of flowering plants. New York: Columbia University Press, 1981. 1262p.

DANIEL, J.F.S. et al. Free radical scavenging activity of Pfaffia glomerata (Spreng.) Pedersen (Amaranthaceae). Indian Journal Pharmacology, v.37, p.174-8, 2005.

EAPEN, S.; TIVAREKAR, S.; GEORGE, L. Thidiazuron induced shoot regeneration in pigeonpea (Cajanus cajan L.). Plant Cell, Tissue and Organ Culture, v.53, p.21720, 1998.

FIGUEIREDO, L.S. et al. Comportamento de acessos de Pfaffia glomerata nas condições de campos de Goytacazez-RJ. Revista Brasileira de Plantas Medicinais, v.7, n.1, p.67-72, 2004.

FLORES, R. et al. Efeito da sacarose e do benomyl na multiplicação in vitro da macieira. Pesquisa Agropecuária Brasileira, v.34. n.12, p.2363-8, 1999.

FLORES, R.; NICOLOSO, F.T.; MALDANER, J. Propagação clonal rápida de Pfaffia tuberosa (Spreng.) Hicken utilizando thidiazuron. Revista Brasileira de 
Plantas Medicinais, v.9, n.1, p.1-7, 2007.

FREITAS, C.S. et al. Actions of crude hydroalcoholic extract of Pfaffia sp. on gastrointestinal tract. Brazilian Archives of Biology an Technology, v.46, n.3, p.1167-79. 2003. GEORGE, E. Plant propagation by tissue culture: the tecnology. Eversley: Exegetics Limited, 1996. 758p. HOWELL, S.H.; LALL, S.; CHE, P. Cytokinins and shoot development. Trends in Plant Science, v.8, p.453-9, 2003. HUETTEMAN, C.A.; PREECE, J.E. Thidiazuron: a potent cytokinin for woody plant tissue culture. Plant Cell, Tissue and Organ Culture, v.33, n.2, p.105-19, 1993.

KHAWAR, K.M. et al. Effect of thidiazuron on shoot regeneration from different explants of lentil (Lens culinaris Medik.) via organogenesis. Turk Journal Botany, v.28, p.421-6, 2004.

MANTELL, S.H. et al. Princípios de biotecnologia em plantas: uma introdução à engenharia genética em plantas. Ribeirão Preto: SBG, 1994. 344p.

MARQUES, L.C. et al. Psychopharmacological assessment of Pfaffia glomerata roots (extract BNT-08) in rodents. Phytotherapy Research, v.18, n.7, p.566-72, 2004. MOK, M.C. et al. Biological and biochemical effects of cytokinin-active phenylurea derivates in tissue culture systems. HortScience, v.22, n.6, p.1194-7, 1987.

MURASHIGUE, T.; SKOOG, F. A revised medium for rapid growth and bioassays with tabacco tissue cultures. Physiologia Plantarum, v.5, p.473-97, 1962.

NETO, A.G.; COSTA, J.M.L.C.; BELATI, C. Analgesic and anti-inflammatory activity of a crude root extract of Pfaffia glomerata (Spreng.) Pedersen. Journal of Etnopharmacology, v.96, p.87-91, 2005.
NICOLOSO, F.T.; FORTUNATO, R.P.; FOGAÇA, M.A. Influência da posição da estaca no ramo sobre o enraizamento de Pfaffia glomerata (Spreng.) Pedersen em dois substratos. Ciência Rural, v.29, n.2, p.277-83, 1999. NICOLOSO, F.T. et al. Micropropagação do ginseng brasileiro (Pfaffia glomerata (Spreng.) Pedersen). Revista Brasileira de Plantas Medicinais, v.3, n.2, p.11-8, 2001. PATTNAIK, S.K.; SAHOO, Y.; CHAND, P.K. Migropropagation of a fruit tree, Morus australis Poir. Syn. M. acidosa Griff. Plant Cell Report, v.15, p.841-5, 1996.

RAO, S.; RAVISHANKAR, G.A. Plant cell cultures: chemical factories of secondary metabolites. Biotecnology Advances, v.20, p.101-53, 2002.

RATES, S.M.K.; GOSMANN, G. Gênero Pfaffia: aspectos químicos, farmacológicos e implicações para o seu emprego terapêutico. Revista Brasileira de Farmacognosia, v.12, n.2, p.85-93, 2002.

SANCHES, N.R. et al. Avaliação da atividade antihiperglicemiante da Pfaffia glomerata (Spreng.) Pedersen (Amaranthaceae). Acta Scientiarum, v.23, n.2, p.613-7, 2001.

SHIOBARA, Y. et al. A nortriterpenoid, triterpenoid and ecdysteroids from Pfaffia glomerata. Phytochemistry, v.32, n.6, p.1527-30, 1993.

ZAERR, J.B.; MAPES, M.O. Action of growth regulators. In:BONGA, J.M.; DURZAN, D.J. (Eds.). Tissue culture in forestry. Dordrech: Martinus Nijhoff, 1985. p.231-55.

ZIMMER, A.R. et al. HPLC method for the determination of ecdysterone in extractive solution from Pfaffia glomerata. Journal of Pharmaceutical and Biomedical Analysis, v.40, p.450-3, 2006. 